\title{
Атомный состав и электрофизические характеристики эпитаксиальных слоев CVD алмаза, легированных бором
}

\author{
() Е.А. Суровегина ${ }^{+}$, Е.В. Демидов ${ }^{+}$, М.Н. Дроздов ${ }^{+}$, А.В. Мурель ${ }^{+}$О.И. Хрыкин ${ }^{+}$, \\ В.И. Шашкин ${ }^{+}$, М.А. Лобаев*, А.М. Горбачев*, А.Л. Вихарев*, С.А. Богданов*, \\ В.А. Исаев*, А.Б. Мучников*, В.В. Чернов*, Д.Б. Радищев*, Д.Е. Батлер*
}

+ Институт фризики микроструктур Российской академии наук, 607680 Нижний Новгород, Россия

* Институт прикладной физики Российской академии наук, 603950 Нижний Новгород, Россия

E-mail: suroveginaka@ipmras.ru

(Получена 27 апреля 2016 г. Принята к печати 10 мая 2016 г.)

Приведены результаты анализа атомного состава, уровня легирования и подвижности дырок в эпитаксиальных слоях CVD (chemical vapor deposition) алмаза при легировании бором. Показаны возможности однородного легирования бором в диапазоне от $5 \cdot 10^{17}$ до $\sim 10^{20}$ ат/см ${ }^{3}$ и $\delta$-легирования с поверхностной концентрацией $(0.3-5) \cdot 10^{13}$ ат/см². Определены режимы прецизионного ионного травления структур, сформированы барьерные и омические контакты к слоям.

\section{1. Введение}

В последнее время наблюдается рост интереса к получению и исследованию эпитаксиальных слоев CVD алмаза. Уникальные свойства таких структур открывают перспективы по созданию на их основе различных элементов мощной СВЧ-электроники [1]. Однако большие значения энергии активации примеси создают проблемы получения легированных слоев с необходимыми для полупроводниковых приборов свойствами. Поэтому многими группами [2-9] ведутся исследовательские работы по изучению возможности получения эпитаксиальных пленок алмаза электронного и дырочного типов проводимости при комнатной температуре. С этой целью применяется сильное легирование, которое позволяет существенно снизить энергию активации примеси. Перспективным является использование $\delta$-легированных слоев в качестве канала полевых транзисторов, которое позволяет достичь компромисса между высокой проводимостью и подвижностью носителей [10].

\section{2. Методика эксперимента}

Эпитаксиальные слои алмаза выращивались методом CVD на монокристаллических подложках HPHT алмаза с ориентацией (100) в микроволновом CVD реакторе $[11,12]$. Для однородного легирования бором CVD алмаза бор добавлялся в состав газовой смеси c помощью специально разработанного барботера, позволяющего подавать поток несущего газа (водорода) через раствор триметилбората $\mathrm{B}\left(\mathrm{OCH}_{3}\right)_{3}$ в этаноле. Для создания в CVD алмазе сильно легированных $\delta$-слоев использовалась созданная в ИПФ РАН установка [13]. Установка позволяла получать $\delta$-легированные слои нанометровой толщины за счет ламинарного потока и быстрого переключения газов. В качестве источника бора использовался диборан $\left(\mathrm{B}_{2} \mathrm{H}_{6}\right)$. Размер подложек $3 \times 3 \mathrm{MM}^{2}$.
Поверхность получаемых эпитаксиальных слоев CVD алмаза была гладкая, на ACM изображении, приведенном на рис. 1, величина шероховатости $\sigma$ не превышает 0.24 нм. Нами были отработаны технологии фотолитографии, прецизионного ионного травления и электронно-лучевого напыления металлов для формирования омических и барьерных контактов. Для барьерных контактов использовали $\mathrm{Al}$ (высота барьера Шоттки $\sim 1$ эВ, фактор неидеальности $\sim 2$ ). Омические контакты были трехслойными - Ti/Mo/Au. Для уменьшения удельного контактного сопротивления $\rho_{c}$ проводился отжиг в течение $10 \mathrm{~min}$ при температуре $400^{\circ} \mathrm{C}$ в инертной атмосфере. Измерялись вольт-амперные характеристики (BAX) (система Keithley SCS 4200); вольтфарадные характеристики $(C-V)$ (LCR Agilent E4980A, диапазон частот 20 Г-2МГц); эффект Холла в геометрии Ван-дер-Пау (В-д-П), удельные и контактные сопротивления - методом длинной линии (TLM). Ко-

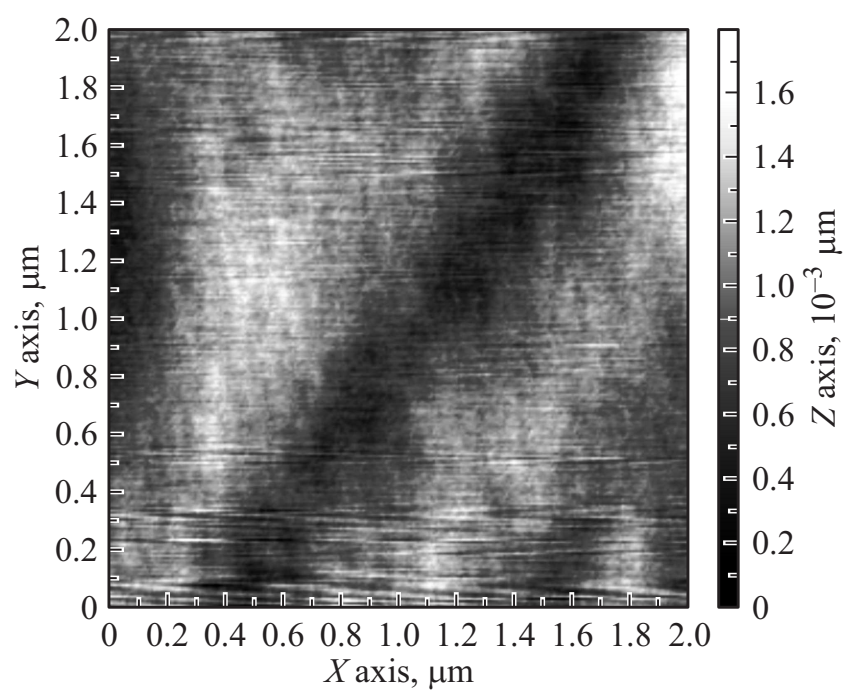

Рис. 1. АСМ изображение структуры эпитаксиального алмаза E35-14. 
личественный анализ концентрации атомов бора проводился методом вторично-ионной масс-спектрометрии (BИМС) на установке TOF.SIMS-5. Для калибровки чувствительности по бору была изготовлена серия тестовых структур - слоев алмаза, имплантированных ионами бора ${ }^{11} \mathrm{~B}$ с энергией 50 кэВ и разной дозой.

\section{3. Результаты и обсуждение}

\section{1. Однороднолегированные образцы алмаза}

Поскольку бор является достаточно глубоким акцепторным уровнем $\left(E_{v}+0.37\right.$ эВ), то для получения высокой проводимости при комнатной температуре требуется сильное легирование. Образцы однороднолегированных бором слоев эпитаксиального алмаза измерялись методами ВИМС, $C-V$ и В-д-П, результаты которых приведены в табл. 1. Концентрация атомов бора по измерению ВИМС превышала $10^{19} \mathrm{~cm}^{-3}$, а концентрация дырок варьировалась от $10^{18}$ до $4 \cdot 10^{19} \mathrm{~cm}^{-3}$. Такое сильное легирование приводит к очень низкой подвижности носителей, не превышающей $10 \mathrm{~cm}^{2} /(\mathrm{B} \cdot \mathrm{c})$, что является препятствием для получения высокочастотных приборов. Однако сильно легированные слои могут быть с успехом использованы для создания омических контактов. Минимальные значения $\rho_{c}=7.5 \cdot 10^{-4} \mathrm{OM} \cdot \mathrm{cm}^{2}$ были получены для слоя В11 с легированием $4 \cdot 10^{19} \mathrm{~cm}^{-3}$.

\section{2. Дельта-легированные слои бора в алмазе}

Для изучения $\delta$-легированных бором слоев алмаза была выращена структура с тремя $\delta$-слоями, расположенными на различном расстоянии от поверхности (образец S09). Измерения ВИМС подтверждают их наличие, причем, как видно из рис. 2, средний слой

Таблица 1. Параметры однородно легированных бором образцов алмаза В8-B12

\begin{tabular}{l|c|c|c|c}
\hline \multicolumn{1}{c|}{ Параметр } & $\mathrm{B} 8$ & $\mathrm{~B} 9$ & $\mathrm{~B} 11$ & $\mathrm{~B} 12$ \\
\hline$\mu_{p}, \mathrm{~cm}^{2} /(\mathrm{B} \cdot \mathrm{c})$ & 8 & 2 & & \\
$R, \mathrm{Oм} / \square$ & 3000 & 1700 & 340 & \\
$p_{\mathrm{B}-\text {--П }}, \mathrm{cm}^{-3}$ & $1.2 \cdot 10^{18}$ & $9 \cdot 10^{18}$ & & \\
$p_{C-V}, \mathrm{~cm}^{-3}$ & $4.5 \cdot 10^{18}$ & $5 \cdot 10^{18}$ & $4 \cdot 10^{19}$ & $3 \cdot 10^{18}$ \\
$N_{\mathrm{B} и м С}$, ат $/ \mathrm{cm}^{-3}$ & & $1.2 \cdot 10^{19}$ & &
\end{tabular}

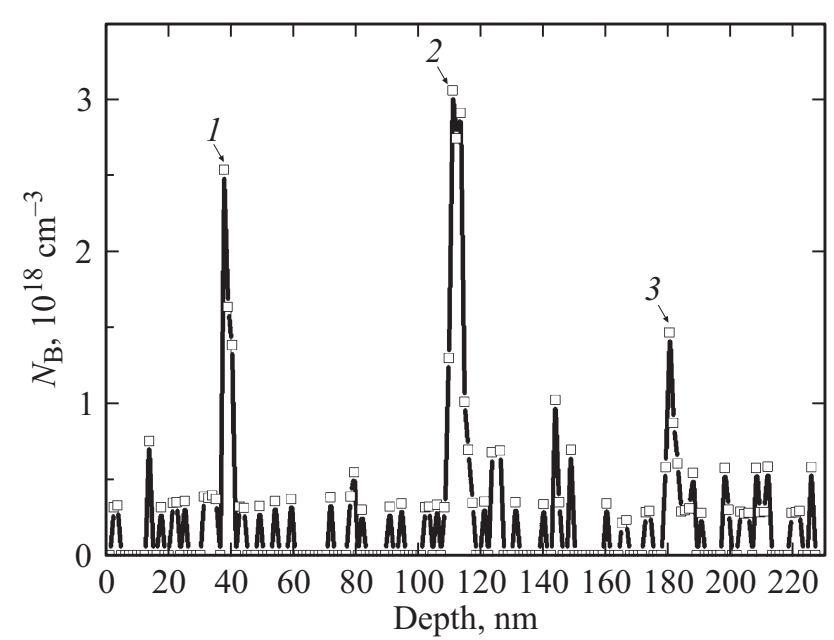

Pис. 2. Распределение бора в структуре S09, измеренное методом ВИМС. Поверхностная плотность атомов бора в $\delta$-слоях, $\mathrm{cm}^{-2}: 1-1 \cdot 10^{12}, 2-7 \cdot 10^{12}, 3-7 \cdot 10^{11}$.

обладает наибольшей плотностью. Параметры $\delta$-слоев приведены в табл. 2.

Пиковая концентрация атомов бора в максимуме, определенная методом ВИМС, не является достаточно корректной величиной вследствие присущего методу аппаратного расплывания профиля по глубине, сопровождающего измерение очень тонких (порядка нескольких постоянных решетки) слоев примеси. Поэтому в отличие от поверхностной плотности, определяемой интегрированием профиля по глубине, эти значения являются приближенными.

Метод Ван-дер-Пау дает значение поверхностной плотности носителей $\left(6 \cdot 10^{11} \mathrm{~cm}^{-2}\right)$, на порядок меньшее, чем поверхностная концентрация бора из ВИМС (табл. 2), что свидетельствует о неполной ионизации примеси при комнатной температуре. При этом, как будет показано далее, эта приведенная плотность дырок относится к среднему $\delta$-слою, так как крайние слои оказываются обедненными. Подвижность носителей в $\delta$-слое составляет $240 \mathrm{~cm}^{2} /(\mathrm{B} \cdot \mathrm{c})$, что существенно выше, чем в однородно легированных структурах.

Измерения ВФХ структуры S09 с барьером Шоттки на различных частотах тестового сигнала показали сильную частотную дисперсию емкости, что подтверждается рис. 3 для емкости при нулевом напряжении смещения $C_{0}(f)$. Такое поведение ВФХ наблюдается в

Таблица 2. Параметры $\delta$-слоев бора в структуре S09

\begin{tabular}{c|c|c|c|c|c|c}
\hline & \multicolumn{3}{|c|}{ ВИМС } & Ван-дер-Пау & \multicolumn{2}{c}{ ВФХ } \\
\cline { 2 - 7 } & $\begin{array}{c}\text { Расстояние } \\
\text { от поверхности, нм }\end{array}$ & $\begin{array}{c}\text { Концентрация } \\
\text { атомов бора } \\
\text { в максимуме, см }\end{array}$ & $\begin{array}{c}\text { Поверхностная } \\
\text { концентрация } \\
\text { бора, см }\end{array}$ & $\begin{array}{c}\text { Поверхностная } \\
\text { концентрация } \\
\text { дырок, см }\end{array}$ & $\begin{array}{c}\text { Поверхностная } \\
\text { концентрация } \\
\text { дырок, см }\end{array}$ & $\begin{array}{c}\text { Расстояние } \\
\text { от поверхности, нм }\end{array}$ \\
\hline 1 & 40 & $5 \cdot 10^{18}$ & $1 \cdot 10^{12}$ & & \\
2 & 120 & $8 \cdot 10^{18}$ & $7 \cdot 10^{12}$ & $6 \cdot 10^{11}$ & $6.2 \cdot 10^{11}$ & 100 \\
3 & 180 & $4 \cdot 10^{18}$ & $0.7 \cdot 10^{12}$ & &
\end{tabular}


большинстве работ, посвященных изучению импеданса структур на алмазе [14-16]. Причиной частотной дисперсии емкости является наличие большого последовательного сопротивления (от единиц до десятков кОм), проявляющее себя также при измерении прямых ветвей ВАХ. Поэтому корректные измерения ВФХ можно проводить только на низких частотах $(\leq 3 \kappa$ кц). На рис. 4 приведены температурные зависимости ВФХ, измеренные на частоте 3 кГц. Обработка их по известным формулам позволяет рассчитать $C V$-профили, характерные для встроенных $\delta$-легированных слоев. Эти профили описывают средний $\delta$-слой (рис. 5), расположенный на глубине $\sim 100$ нм, а крайние слои - обеднены. Поверхностная плотность дырок, оцениваемая по интегралу $C V$-профиля по глубине, составляет $6.2 \cdot 10^{11} \mathrm{~cm}^{-2}$, что согласуется с холловскими измерениями $\left(6 \cdot 10^{11} \mathrm{~cm}^{-2}\right)$ (см. табл. 2). С ростом температуры поверхностная плотность дырок возрастает, что видно из зависимости Аррениуса (см. вставку на рис. 5), которая позволяет оценить энергию активации примеси. Для примесного

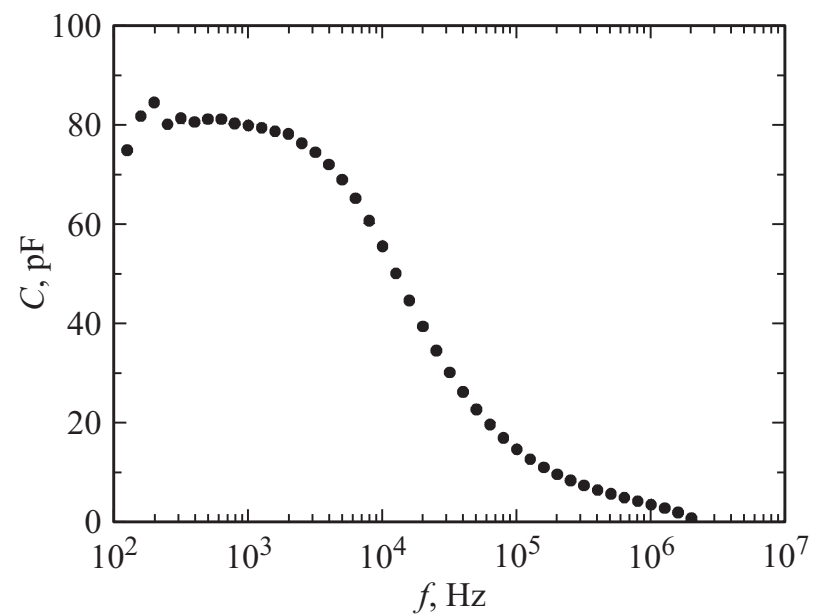

Рис. 3. Частотная зависимость емкости барьера Шоттки структуры S09 при нулевом напряжении смещения.

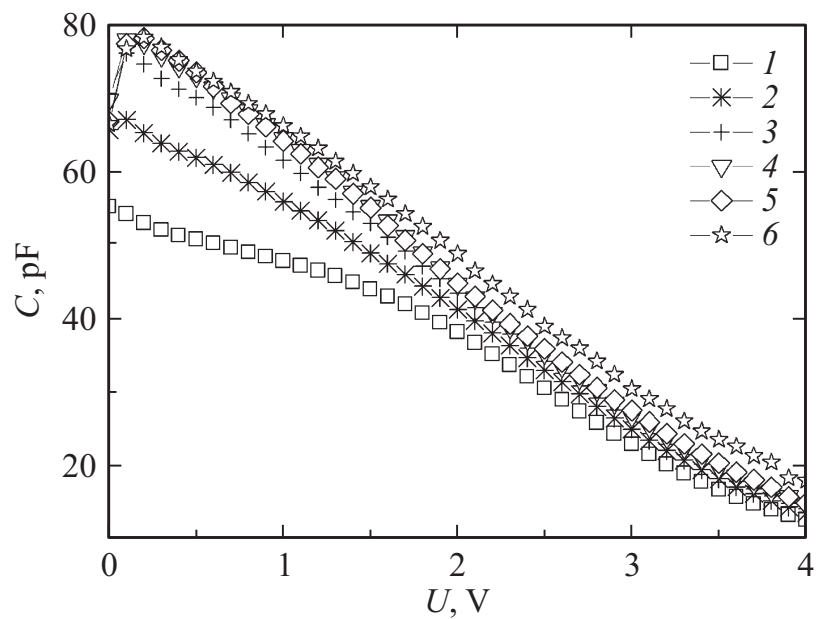

Рис. 4. Температурная зависимость ВФХ для структуры S09 с $\delta$-легированным слоем, К: $1-300,2-320,3-340$, $4-360,5-380,6-400$. Частота измерения 3 кГц.

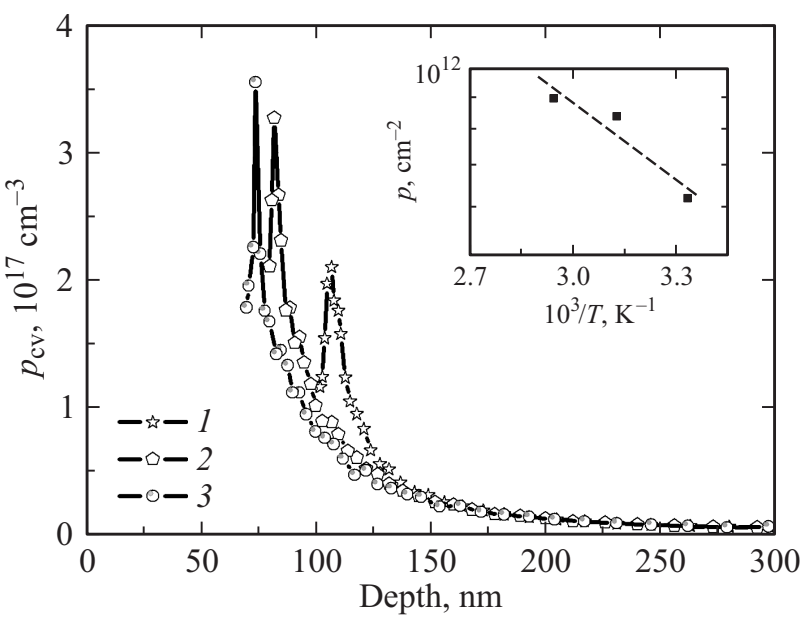

Рис. 5. Температурная зависимость $C V$-профиля для структуры S09 с $\delta$-легированным слоем, К: $1-300,2-320$, 3 - 340. На вставке показана температурная зависимость поверхностной концентрации дырок в координатах Аррениуса. Энергия активации носителей $\sim 0.17$ эВ.

полупроводника в области неполной ионизации примеси справедливо следующее уравнение [17]:

$$
p=\sqrt{\left(N_{a}-N_{d}\right) \frac{N_{v}}{g_{a}}} \exp \left(\frac{-E_{a}}{2 k_{\mathrm{B}} T}\right),
$$

где $N_{a}$ - концентрация акцепторов, $N_{d}$ - концентрация компенсирующих доноров, $N_{v}$ - плотность состояний в валентной зоне, $g_{a}$ - фактор вырождения, $E_{a}$ - энергия активации примеси, $T$ - температура, $k_{\mathrm{B}}-$ постоянная Больцмана.

По наклону прямой на вставке рис. 5 можно оценить энергию активации примеси, которая составляет $\sim 0.17$ эВ. Зависимость энергии активации бора $E_{a}$ в алмазе от его концентрации описывается эмпирической формулой [18]:

$$
E_{a}=E_{0}-\alpha \cdot N_{a}^{1 / 3},
$$

где $E_{0}$ - глубина залегания примесного уровня бора в алмазе, равная 0.37 эВ, $N_{a}$ - концентрация бора, $\alpha-$ коэффициент, равный $5.1 \cdot 10^{-8}$ эВ $\cdot$ см.

Понижение энергии активации обусловлено уменьшением среднего расстояния между акцепторами. Если воспользоваться этой формулой, то по полученному значению энергии активации $(0.17$ эВ) пиковая концентрация бора в $\delta$-слое должна составлять $\sim 8 \cdot 10^{19} \mathrm{~cm}^{-3}$. Предположив, что толщина $\delta$-слоя равна $\sim 1$ нм [1] (т. е. около трех постоянных решетки алмаза), из слоевой концентрации бора (по ВИМС) получим значение концентрации в максимуме $\sim 7 \cdot 10^{19} \mathrm{~cm}^{-3}$, что приблизительно согласуется с найденным значением из энергии активации.

Выращенная MESFET-транзисторная структура E35-14 содержит сильно легированный контактный слой и канал, содержащий $\delta$-легированный слой. Профиль легирования, измеренный методом ВИМС, приведен на рис. 6. Контактный слой толщиной 15 нм легирован бором до концентрации $10^{20} \mathrm{aT} / \mathrm{cm}^{3}$. Поверхностная кон- 


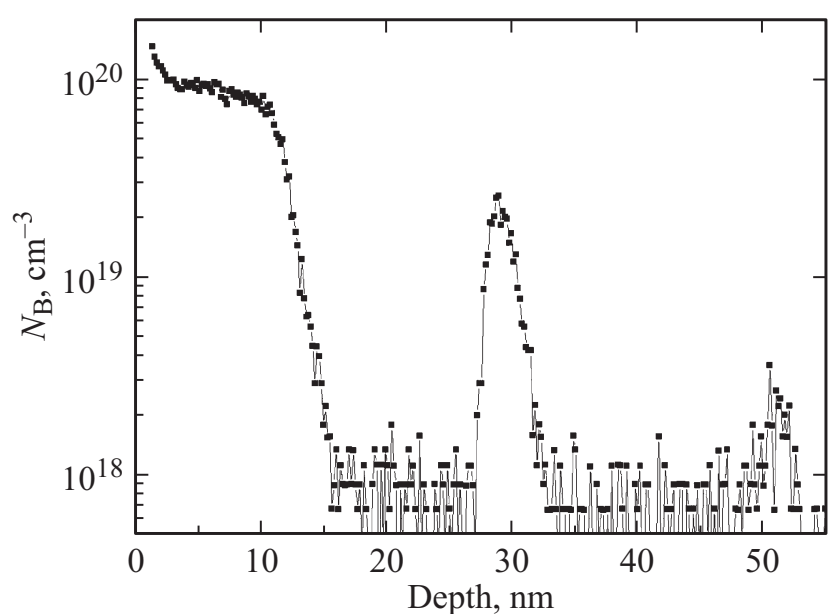

Рис. 6. Распределение бора в транзисторной структуре Е35-14, измеренное методом ВИМС.

центрация $\delta$-слоя, расположенного на глубине 30 нм, $2.4 \cdot 10^{12}$ ат $/ \mathrm{cm}^{2}$. Предполагается с помощью технологии прецизионного травления с использованием ионов кислорода сформировать затвор на необходимом расстоянии от канала, который позволит осуществить модуляцию его проводимости.

\section{4. Заключение}

В работе исследованы эпитаксиальные слои CVD алмаза, легированные бором. Реализовано однородное легирование бором в диапазоне от $5 \cdot 10^{17}-10^{20} \mathrm{aт} / \mathrm{cm}^{3}$ и $\delta$-легирование с поверхностной концентрацией $(0.3-5) \cdot 10^{13}$ ат/см ${ }^{2}$. Концентрация дырок растет с увеличением концентрации атомов бора и температуры, что связано с уменьшением энергии активации. Минимальное сопротивление слоев с объемным легированием $R \sim 300$ Ом/ $\square$. Одиночные $\delta$-слои имеют $R \geq 4000$ Ом/ $\square$. Определены режимы прецизионного ионного травления, отработана лабораторная технология формирования барьерных и омических контактов $\left(\rho_{c}=7.5 \cdot 10^{-4} \mathrm{OM} \cdot \mathrm{cm}^{2}\right)$.

Работа выполнена при финансовой поддержке гранта Правительства РФ по постановлению 220, договор № 14.В25.31.0021 с ведущей организацией ИПФ РАН. В работе использовалось оборудование ЦКП „Физика и технология микро- и наноструктур“.

Авторы выражают благодарность М.В. Зориной за АСМ исследования.

\section{Список литературы}

[1] E. Kohn, A. Denisenko. Thin Sol. Films, 515, 4333 (2007).

[2] T. Kobayashi, T. Ariki, M. Iwabuchi, T. Maki, S. Shikama, S. Suzuki. J. Appl. Phys., 76 (3), 1977 (1994).

[3] A. Aleksov, A. Vescanb, M. Kunzea, P. Gluchea, W. Eberta, E. Kohna, A. Bergmeierb, G. Dollingerb. Diamond Relat. Mater., 8 (2-5), 941 (1999).
[4] H. El-Haji, A Denisenko, A. Kaiser, R.S. Balmer. Diamond Relat. Mater., 17 (7-10), 1259 (2008).

[5] R.S. Balmer, I. Friel, S. Hepplestone, J. Isberg, M.J. Uren, M.L. Markham, N.L. Palmer, J. Pilkington, P. Huggett, S. Majdi, R. Lang. J. Appl. Phys., 113 (3) (2013).

[6] N. Tumilty, J. Welch, R.S. Balmer, C. Wort, R. Lang, R.B. Jackman. J. Appl. Phys., 106 (10), 103707 (2009).

[7] G. Chicot, A. Fiori, P.N. Vople, T.N.T. Thi, J.C. Gerbedoen, J. Bousquet, M.P. Alegre, J.C. Pinero, D. Araujo, F. Jomard, A. Soltani, J.C. De Jaeger, J. Morse, J. Hárwig, N. Tranchant, C. Mer-Calfati, J.C. Arnault, J. Delahaye, T. Grenet, D. Eon, F. Omnes, J. Pernot, E. Bustarret. J. Appl. Phys., 116 (8), 083702 (2014).

[8] P.N. Volpe, N. Tranchant, J.C. Arnault, S. Saada, F. Jomard, P. Bergonzo. Phys. Status Solidi RRL, 6 (2), 59 (2012).

[9] A. Fiori, T.N.T. Thi, G. Chicot, F. Jomard, F. Omnés, E. Gheeraert, E. Bustarret. Diamond Relat. Mater., 24, 175 (2012).

[10] E.F. Schubert. Delta-doping of semiconductors (Cambridge University Press, 1996).

[11] А.А. Алтухов, А.Л. Вихарев, А.М. Горбачев, М.П. Духновский, В.Е. Земляков. ФТП, 45, 403 (2011).

[12] А.Л. Вихарев, А.М. Горбачев, В.А. Колданов. Физика плазмы, 31, 376 (2005).

[13] A.L. Vikharev, A.M. Gorbachev, M.A. Lobaev, A.B. Muchnikov, D.B. Radishev, V.A. Isaev, V.V. Chernov, S.A. Bogdanov, M.N. Drozdov, J.E. Butter. Phys. Status Solidi RRL, 10 (4), 324 (2016).

[14] V. Venkatesan, K. Das, J.A. von Windheim, M.W. Geis. Appl. Phys. Lett., 63, 1065 (1993).

[15] W.P. Kang, J.L. Davidson, Y. Gurbuz, D.V. Kerns Citation. J. Appl. Phys., 78, 1101 (1995).

[16] S. Nath, J.I.B. Wilson. Diamond Relat. Mater., 5, 65 (1996).

[17] Saman Majdi. Electronic characterization of CVD diamond (Uppsala, Division of Electricity Department of Engineering Sciences, 2010).

[18] W. Gajewski, P. Achatz, O. Williams, K. Haenen, E. Bustarret, M. Stutzmann, J. Garrido. Phys. Rev. B, 79, 045206 (2009).

Редактор Г.А. Оганесян

\section{Atomic composition and electrical characteristics of boron-doped homoepitaxial CVD diamond layers}

\author{
E.A. Surovegina ${ }^{+}$, E.V. Demidov ${ }^{+}$, M.N. Drozdov ${ }^{+}$, \\ A.V. Murel+, O.I. Khrykin', V.I. Shashkin ${ }^{+}$, \\ M.A. Lobaev*, A.M. Gorbachev*, A.L. Viharev*, \\ S.A. Bogdanov*, V.A. Isaev*, A.B. Muchnikov*, \\ V.V. Chernov*, D.B. Radishchev*, J.E. Batler* \\ + Institute for Physics of Microstructures, \\ Russian Academy of Sciences, \\ 607680 Nizhny Novgorod, Russia \\ * Institute of Applied Physics, \\ Russian Academy of Sciences, \\ 603950 Nizhny Novgorod, Russia
}

\footnotetext{
Abstract Atomic composition, doping level and hole mobility in boron-doped homoepitaxial CVD diamond layers have been investigated. The possibilities of a uniform doping with boron in the range of $5 \cdot 10^{17}-10^{20}$ at $/ \mathrm{cm}^{3}$ have been shown along with the $\delta$-doping with surface concentration up to $(0.3-5) \cdot 10^{13}$ at $/ \mathrm{cm}^{2}$. Optimal modes for precise ion etching, barrier and ohmic contact fabrication have been found.
} 